Elsevier required licence: (c) <2019>. This manuscript version is made available under the CC-BY-NC-ND 4.0 license http://creativecommons.org/licenses/by-nc-nd/4.0/

The definitive publisher version is available online at https://doi.org/10.1016/j.scitotenv.2018.12.349 


\title{
Fuel consumption and emissions performance under real driving: comparison between hybrid and conventional vehicles
}

\author{
Yuhan Huang ${ }^{1, *}$, Nic C. Surawski ${ }^{1}$, Bruce Organ ${ }^{1,2}$, John L. Zhou ${ }^{1, *}$, Oscar H. H. Tang ${ }^{2}$, \\ Edward F. C. Chan ${ }^{1,3}$
}

\begin{abstract}
${ }^{1}$ School of Civil and Environmental Engineering, University of Technology Sydney, NSW 2007, Australia

${ }^{2}$ Jockey Club Heavy Vehicle Emissions Testing and Research Centre, Vocational Training Council, Hong Kong

${ }^{3}$ Faculty of Science and Technology, Technological and Higher Education Institute of Hong Kong, Hong Kong
\end{abstract}

Corresponding authors:

Professor John L. Zhou, Email: junliang.zhou@uts.edu.au

Dr Yuhan Huang, Email: yuhan.huang@uts.edu.au

Please cite this article as:

Y. Huang, N.C. Surawski, B. Organ, J.L. Zhou, O.H.H. Tang, E.F.C. Chan. Fuel consumption and emissions performance under real driving: Comparison between hybrid and conventional vehicles. Science of the Total Environment 2019; 659: 275-282. DOI: https://doi.org/10.1016/j.scitotenv.2018.12.349 


\begin{abstract}
Hybrid electric vehicles (HEVs) are perceived to be more energy efficient and less polluting than conventional internal combustion engine (ICE) vehicles. However, increasing evidence has shown that real-driving emissions (RDE) could be much higher than laboratory-type approval limits and the advantages of HEVs over their conventional ICE counterparts under real-driving conditions have not been studied extensively. Therefore, this study was conducted to evaluate the real-driving fuel consumption and pollutant emissions performance of HEVs against their conventional ICE counterparts. Two pairs of hybrid and conventional gasoline vehicles of the same model were tested simultaneously in a novel convoy mode using two portable emission measurement systems (PEMSs), thus eliminating the effect of vehicle configurations, driving behaviour, road conditions and ambient environment on the performance comparison. The results showed that although real-driving fuel consumption for both hybrid and conventional vehicles were 44\%-100\% and 30\%-82\% higher than their laboratory results respectively, HEVs saved 23\%-49\% fuel relative to their conventional ICE counterparts. Pollutant emissions of all the tested vehicles were lower than the regulation limits. However, HEVs showed no reduction in $\mathrm{HC}$ emissions and consistently higher $\mathrm{CO}$ emissions compared to the conventional ICE vehicles. This could be caused by the frequent stops and restarts of the HEV engines, as well as the lowered exhaust gas temperature and reduced effectiveness of the oxidation catalyst. The findings therefore show that while achieving the fuel reduction target, hybridisation did not bring the expected benefits to urban air quality.
\end{abstract}

Keywords: Hybrid electric vehicles; Conventional vehicles; Real-driving emissions; Portable emission measurement system; Convoy testing mode

\title{
Graphic abstract
}
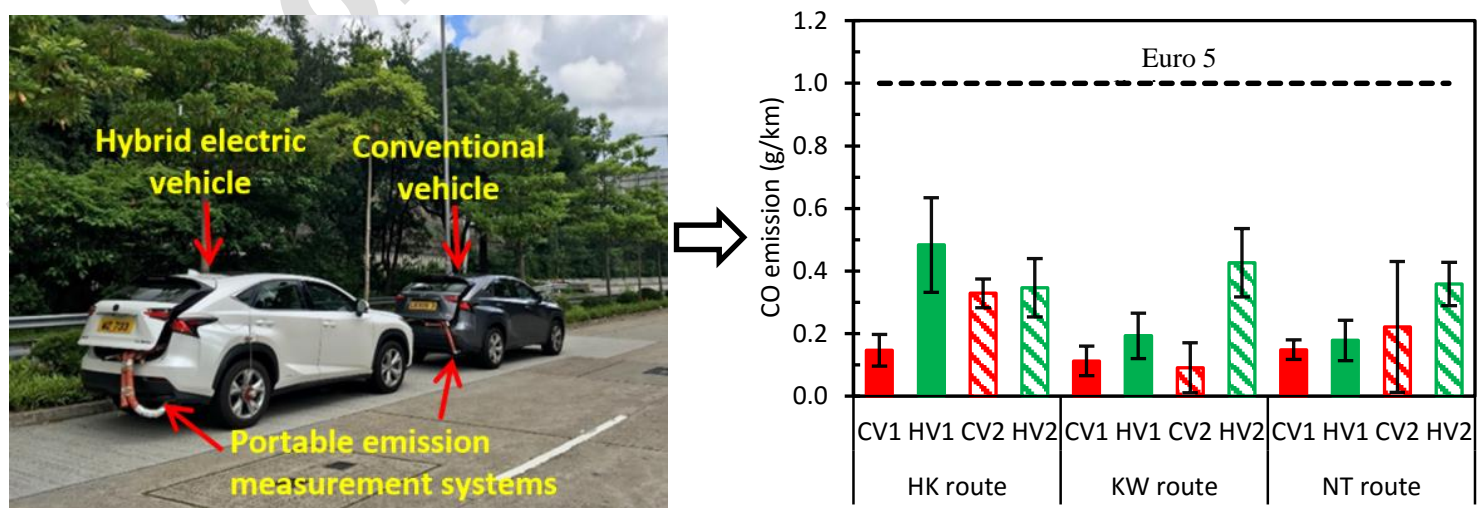


\section{Highlights}

- Two pairs of HEVs and ICE vehicles were tested in a novel convoy mode using PEMS.

- Both HEVs and ICE vehicles had higher RDE fuel consumption than laboratory results.

- HEVs saved 23\%-49\% fuel relative to their ICE counterparts in real-driving.

- HEVs showed no reduction in HC and consistently higher CO compared to ICE vehicles.

\section{Abbreviations}

ANOVA: Analysis of Variance

$\mathrm{CR}$ : Percentage of $\mathrm{CO}_{2}$ reduction of $\mathrm{HV}$ over $\mathrm{CV}$

$\mathrm{CV}$ : Conventional vehicle

EV: Electric vehicle

HEV/HV: Hybrid electric vehicle

FID: Flame ionization detector

FS: Percentage of fuel savings of HV over CV

HK: Hong Kong Island

ICE: Internal combustion engine

KW: Kowloon

MANOVA: Multivariate Analysis of Variance

NDIR: Non-dispersive infrared

NT: New Territories

PEMS: Portable emission measurement system

RDE: Real-driving emissions

SOC: State of charge

TWC: Three-way catalyst 


\section{Introduction}

Road transport is a significant sector for energy consumption and $\mathrm{CO}_{2}$ emissions, and is increasing due to economic and population growth (Huang et al., 2018a; Zahedi et al., 2019). The 2017 International Energy Agency (IEA) data showed that the energy use in transport significantly increased from $23 \%$ of total final consumption in 1971 to $29 \%$ in 2015 (IEA, 2017). Meanwhile, exposure to poor air quality continues to be a critical issue concerning public health worldwide. The World Health Organisation (WHO) estimated that ambient air pollution accounted for 4.2 million premature deaths per year globally (WHO, 2018). Although many sources have contributed to this problem, motor vehicles are the main source of air pollution in urban areas (Huang et al., 2018b, c; Khan et al., 2018). Therefore, great efforts have been taken to reduce energy consumption and pollutant emissions from motor vehicles. Hybridisation of vehicle powertrain is one of the technologies to address these issues (Rezaei et al., 2017).

Intuitively, hybrid electric vehicles (HEVs) are believed to be more fuel efficient and less polluting than conventional internal combustion engine (ICE) vehicles (Franco et al., 2016; He et al., 2017; Rezaei et al., 2017; Sun et al., 2017). HEVs use ICEs in combination with electric motors to provide propulsion to the wheels either together or separately, and use battery packs as a secondary energy storage system (Liu, 2013; M. Sabri et al., 2016). This configuration enables the vehicle to achieve the best design features of both ICE and electric vehicles (EVs). A rule-based or optimization-based energy management strategy is usually used to maximize the overall powertrain efficiency and to minimize fuel consumption and emissions (Liu et al., 2017; Martinez et al., 2017). In an HEV, the ICE mostly operates within its most efficient region and the electric motor is used in regions where the ICE has low efficiency and high emissions (e.g. idling). In addition, the kinetic energy during braking is captured in HEVs using regenerative braking technology, which is dissipated as heat in conventional ICE vehicles. As a result, HEVs are widely considered as an effective solution to energy and environmental issues associated with fossil fuels. Various vehicle purchase incentives are being used in major automotive countries to promote the market penetration of HEVs, such as China, US, Japan and Europe (Gallagher and Muehlegger, 2011; Hao et al., 2014). In the European Union for example, HEVs are seen as a key vehicle technology for meeting 2020 $\mathrm{CO}_{2}$ emission standards (Mock, 2017).

The performance specifications of HEVs given by the manufacturers are measured in the laboratory, which usually show great advantages relative to conventional ICE vehicles (e.g. 34\% less fuel consumption for a Lexus hybrid NX 300h $(5.00 \mathrm{~L} / 100 \mathrm{~km})$ compared to a conventional NX 200t (7.58 L/100km) (Lexus, 2018)). However, increasing evidence is being reported to reveal the significant gap in fuel consumption, $\mathrm{CO}_{2}$ emissions and diesel $\mathrm{NO}_{\mathrm{x}}$ emissions between laboratory testing and real-world driving (Degraeuwe and Weiss, 2017; Durbin et al., 2018; Fu et al., 2013; Kousoulidou et al., 2013; Weiss et al., 2011). This gap is caused by various factors including driving behaviour, vehicle configurations, traffic, road and weather conditions (Fontaras et al., 2017), which are not well considered in laboratory testing. In addition, automotive manufacturers may only optimise vehicle fuel economy and emissions within the pre-defined laboratory test cycles to obtain the certification to enter a specific market, such as the Volkswagen 
scandal. Therefore, the new Euro 6d and China 6 automotive emission regulations are now enforcing real-driving emissions (RDE) as an additional type approval test (European Commission, 2017; ICCT, 2017a). Since diesel vehicles show significantly bigger discrepancies in $\mathrm{NO}_{\mathrm{x}}$ emissions, the majority of RDE studies concerned diesel vehicles while very few were for gasoline and its HEV counterparts (Degraeuwe and Weiss, 2017; Duarte et al., 2016; Franco et al., 2016; Gallus et al., 2016; Kwon et al., 2017; Mendoza-Villafuerte et al., 2017; O'Driscoll et al., 2016; O'Driscoll et al., 2018; Wang et al., 2017; Zheng et al., 2016). In addition, a direct comparison between hybrid and conventional vehicles has not been conducted because the vehicles used in previous RDE studies were in different models/classes and were tested under different conditions.

As reviewed above, there is a lack of research on the fuel consumption and emission performance of HEVs in comparison to their conventional ICE counterparts under real driving conditions. This study was conducted to fill this research gap with the following novelties. Firstly, two pairs of conventional and hybrid vehicles of the same model were tested, which had the same vehicle configurations and thus enabled a fair performance comparison. Secondly, each pair of conventional and hybrid vehicles were tested on the same route simultaneously in a convoy mode using two sets of portable emission measurement systems (PEMSs). The convoy mode was a novel RDE test approach that eliminated the effect of a number of uncontrollable real-driving conditions on the performance comparison. Thirdly, this research provided insights into the advantages and disadvantages of HEVs over their ICE counterparts in reducing fuel consumption and pollutant emissions under real-driving conditions, and enabled scientific justification on the incentives for HEVs.

The remainder of this paper is organized as follows. Section 2 describes the test vehicles, experimental conditions and procedures, and data processing methods. Section 3 reports and discusses the experimental results in three subsections, including fuel consumption performance, pollutant emissions performance, and uncertainties, statistical analysis and implications. Section 4 concludes this study by summarising the major results.

\section{Materials and Methods}

\subsection{Test Vehicles}

Two pairs of hybrid and conventional gasoline vehicles (Table 1) were recruited for this study. Each pair of vehicles were of the same model series (Lexus NX and Toyota Alphard) with the same dimensions, weight, suspension system and exhaust after-treatment technology, except that one vehicle was powered as a conventional ICE while the other was hybrid. To have comparable vehicle performance (output power and torque), the conventional vehicles are usually equipped with more powerful engines than their hybrid counterparts (engine downsizing (Huang et al., 2015) is a major advantage of HEVs). In this study, CV1 has a turbocharged engine and CV2 has a larger displacement engine. 
Table 1. Specifications of the test vehicles.

\begin{tabular}{|c|c|c|c|c|}
\hline \multirow[b]{2}{*}{ Vehicle ID } & \multicolumn{2}{|c|}{ Pair 1} & \multicolumn{2}{|c|}{ Pair 2} \\
\hline & CV1 & HV1 & CV2 & HV2 \\
\hline Powertrain type & Conventional & Hybrid & Conventional & Hybrid \\
\hline Vehicle model & Lexus NX 200t & Lexus NX 300h & Toyota Alphard 350 & Toyota Alphard Hybrid \\
\hline Model year & 2016 & 2015 & 2015 & 2015 \\
\hline Odometer (km) & 4577 & 12619 & 30713 & 15910 \\
\hline Fuel type & Gasoline & Gasoline & Gasoline & Gasoline \\
\hline Emission standard & Japan 2009 & Japan 2009 & Euro 5 & Japan 2009 \\
\hline Exhaust after-treatment & TWC & TWC & TWC & TWC \\
\hline $\begin{array}{l}\text { Vehicle dimensions } \\
(1 \times w \times h \text { in } \mathrm{mm})\end{array}$ & $4630 \times 1845 \times 1645$ & $4630 \times 1845 \times 1645$ & $4915 \times 1850 \times 1895$ & $4915 \times 1850 \times 1895$ \\
\hline Kerb weight (kg) & $1700-1790$ & $1740-1835$ & 2115 & 2210 \\
\hline Engine type & $\begin{array}{c}1998 \mathrm{cc}, \\
\text { turbo-charged, } \\
\text { L4 16-valve DOHC } \\
\text { VVT-i (8AR-FTS) }\end{array}$ & $\begin{array}{l}2494 \mathrm{cc}, \\
\text { naturally aspirated, } \\
\text { L4 16-valve DOHC } \\
\text { VVT-i (2AR-FXE) }\end{array}$ & $\begin{array}{c}3456 \mathrm{cc}, \\
\text { naturally aspirated, } \\
\text { V6 DOHC 24-value } \\
\text { VVT-i (2GR-FE) }\end{array}$ & $\begin{array}{c}2494 \mathrm{cc}, \\
\text { naturally aspirated, } \\
\text { L4 DOHC 16-valve } \\
\text { VVT-i (2AR-FXE) }\end{array}$ \\
\hline $\begin{array}{l}\text { Fuel consumption from } \\
\text { manufacturer (L/100km) }\end{array}$ & 7.58 & 5.00 & 10.64 & 5.29 \\
\hline
\end{tabular}

\subsection{On-Road Emission Measurement}

Two sets of PEMSs (EMS 5002/3) and exhaust flow meters (Sensors Inc. EFM-HS and GZFULI FLE10) were used to measure the exhaust gas emissions and flow rates (Fig. 1). To validate the two PEMSs, testing had been undertaken to compare the PEMSs with the accredited European light duty vehicle emissions test cell in the Jockey Club Heavy Vehicle Emissions Testing and Research Centre. The PEMSs measured the concentrations of $\mathrm{CO}_{2}, \mathrm{CO}, \mathrm{O}_{2}, \mathrm{HC}$ and $\mathrm{NO}$ in the exhaust. $\mathrm{CO}_{2}, \mathrm{CO}$ and $\mathrm{HC}$ were measured by non-dispersive infrared (NDIR), and $\mathrm{O}_{2}$ and NO was measured by electro-chemical cells. Although flame ionization detector (FID) is more accurate and desirable for $\mathrm{HC}$ measurement, the significantly higher weight and power demand of FID prohibits its use for light duty vehicles in this study. EPA specification mixed gases were used to calibrate the emission analysers and zero calibration checks were performed before each on-road test. Car GPS camcorders were used to record the road and traffic conditions, including vehicle speed, altitude, latitude and longitude. Wheel speed sensors were used to measure vehicle speed. Data acquisition systems were used to record the data from all equipment and sensors at a sampling frequency of $1 \mathrm{~Hz}$. The data acquisition systems also applied data offset time for the flow meters and gas analysers due to the gas transport delays within the PEMSs. All equipment was installed in the cabins of the tested vehicles. External $12 \mathrm{~V}$ batteries were used to power the PEMS so there was no additional power load on the vehicle engine. Both vehicles were warmed up before test so cold start was not included (Degraeuwe and Weiss, 2017; O'Driscoll et al., 2016; Rašić et al., 2017). 


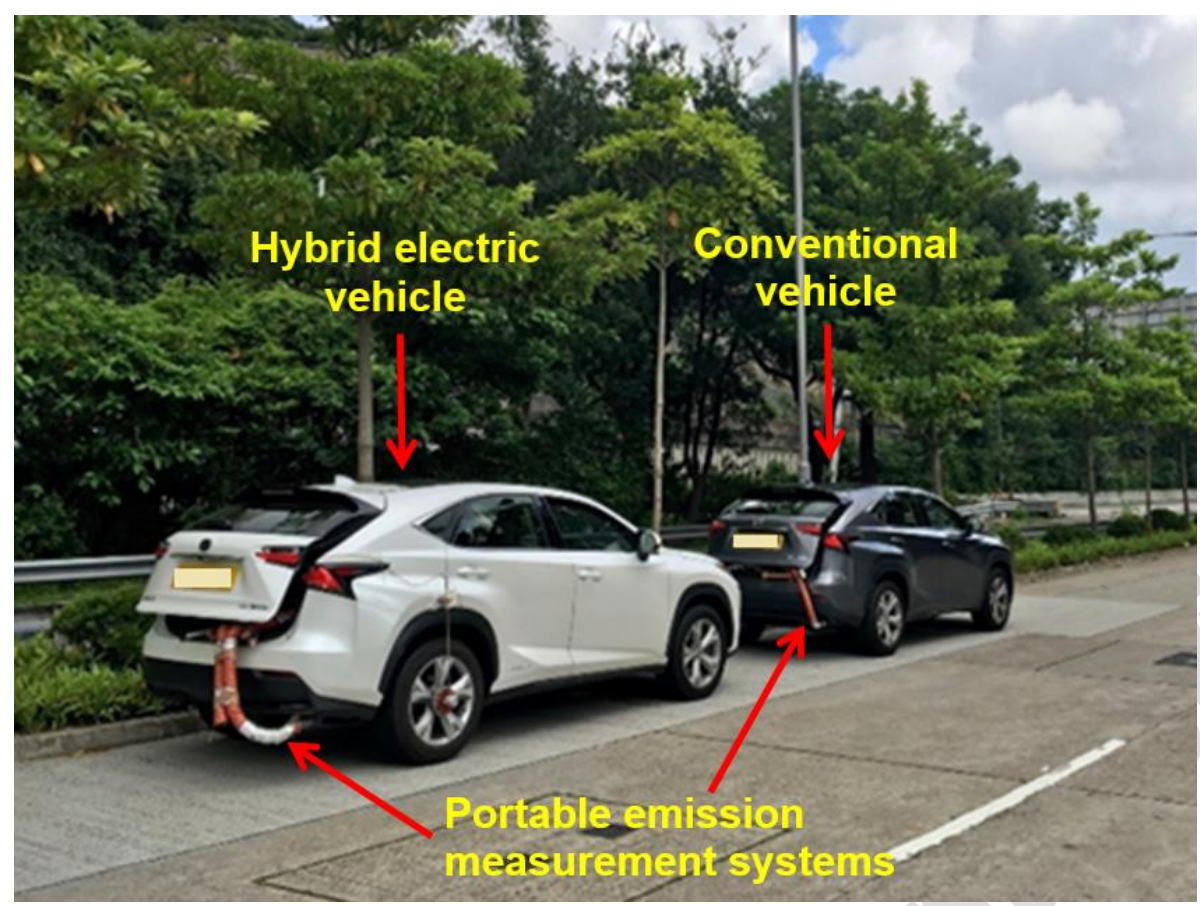

Fig. 1. Setup of RDE convoy test.

Three test routes were chosen to represent real-driving conditions across Hong Kong (Table 2 and Fig. 2). The Hong Kong Island (HK) and Kowloon (KW) routes mainly consisted of urban ( $\leq$ $40 \mathrm{~km} / \mathrm{h}$ ) and rural $(40-70 \mathrm{~km} / \mathrm{h})$ driving conditions. The New Territories (NT) route had more balanced shares for rural, urban and highway $(>70 \mathrm{~km} / \mathrm{h}$ ) driving conditions. Each route was tested five times at the same time around 9 am from Monday to Friday to investigate the effectiveness of hybrid systems in a densely populated city like Hong Kong with heavy traffic congestion problems. Each pair of vehicles were driven at the same time with one following the other, as shown in Fig. 3. Therefore, the driving behaviour, road conditions and ambient environment were kept the same for both vehicles, thus eliminating non-vehicle effects on the performance comparison in this study.

Table 2. Characteristics of the PEMS test routes.

\begin{tabular}{lccccc}
\hline $\begin{array}{l}\text { Route ID (location, origin- } \\
\text { destination) }\end{array}$ & $\begin{array}{c}\text { Urban share } \\
(\%)\end{array}$ & $\begin{array}{c}\text { Rural share } \\
(\%)\end{array}$ & $\begin{array}{c}\text { Motorway } \\
\text { share }(\%)\end{array}$ & $\begin{array}{c}\text { Total distance } \\
(\mathrm{km})\end{array}$ & $\begin{array}{c}\text { Trip duration } \\
(\mathrm{min})\end{array}$ \\
\hline $\begin{array}{l}\text { HK (Hong Kong Island, Chai } \\
\text { Wan - Aberdeen) }\end{array}$ & 26.3 & 72.2 & 1.5 & 16.1 & 29.0 \\
$\begin{array}{l}\text { KW (Kowloon, Elements - } \\
\text { Kwun Tong) }\end{array}$ & 34.3 & 61.8 & 3.9 & 10.1 & 25.5 \\
$\begin{array}{l}\text { NT (New Territories, Hong } \\
\text { Lok Yuen - Kowloon Bay) }\end{array}$ & 25.6 & 42.1 & 32.3 & 23.1 & 46.1 \\
\hline
\end{tabular}




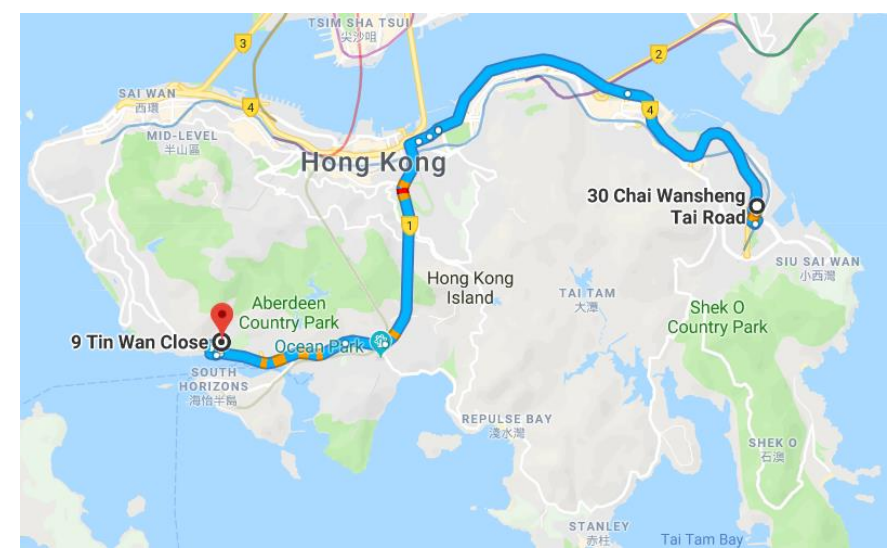

(a) HK route (Chai Wan to Aberdeen): Chai Wansheng Tai Road Island Eastern Corridor - King's Road Tsing Fung Street Flyover - Wong Nai Chung Gap Flyover - Aberdeen Tunnel - Aberdeen Praya Road - Tin Wan Street

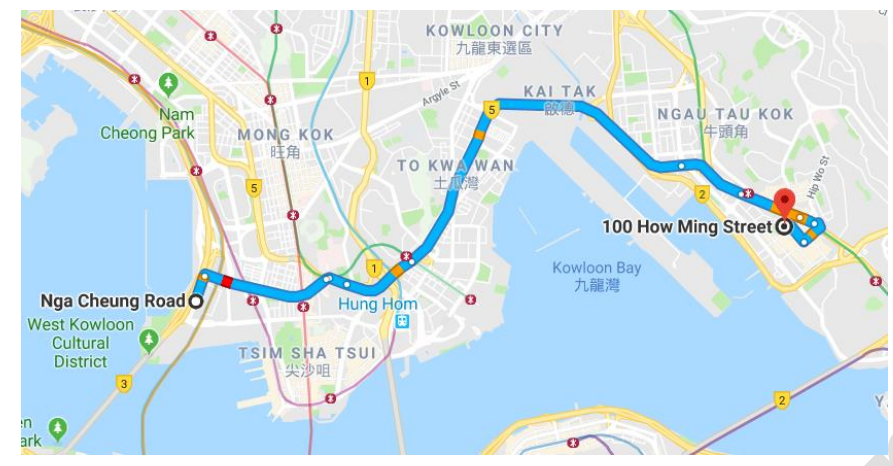

(b) KW route (Elements to Kwun Tong): Elements - Jordan Road - East Kowloon Corridor - Kai Fuk Road Kwun Tong Road - Hoi Yuen Road How Ming Street

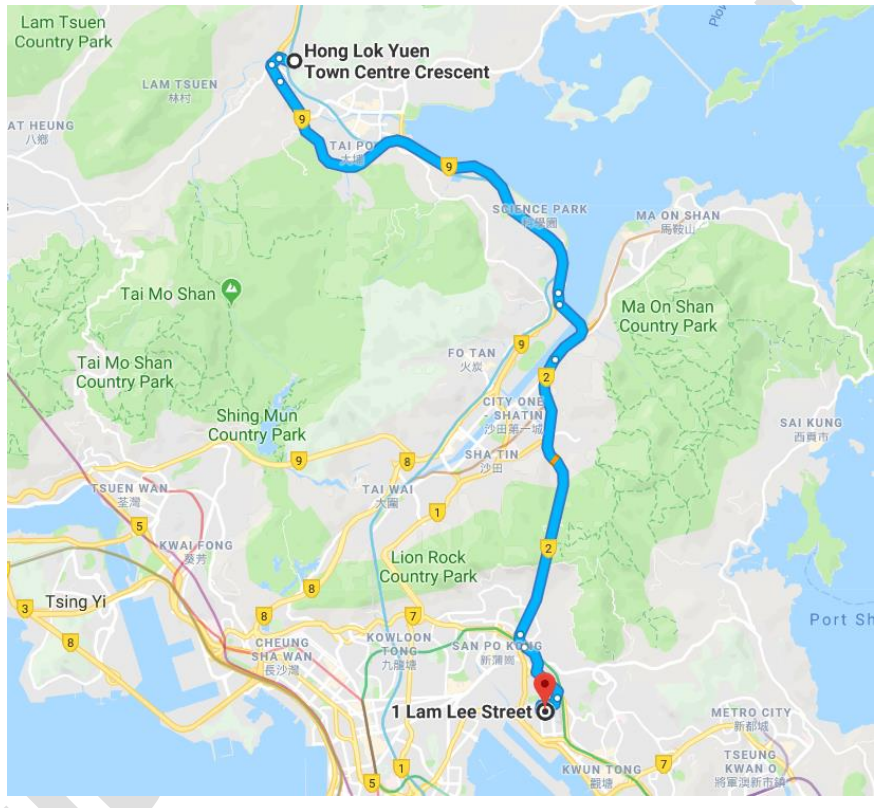

(c) NT route (Hong Lok Yuen to Kowloon Bay): Hong Lok Yuen Town Centre - Tolo Highway - Tate's Cairn Highway - Tate's Cairn Highway Kwun Tong Bypass - Kwun Tong Road - Kai Cheung Road - Lam Hing street Lam Lee Street

Fig. 2. RDE test routes for hybrid and conventional vehicles: (a) Hong Kong Island (HK) route, (b) Kowloon (KW) route, and (c) New Territories (NT) route.

\subsection{Data Processing and Statistical Analysis}

The raw exhaust emissions were measured as volume concentrations ( $\%$ for $\mathrm{CO}_{2}$ and $\mathrm{CO}$, ppm for $\mathrm{HC}$ and $\mathrm{NO})$ with the PEMS and were converted to distance-based emission factors $(\mathrm{g} / \mathrm{km})$ using the Economic Commission for Europe of the United Nations method (UNECE, 2015). Firstly, the measured exhaust mass flow rate $(\mathrm{kg} / \mathrm{h})$ was converted to volume flow rate $\left(\mathrm{m}^{3} / \mathrm{h}\right)$ under 
standard regulation conditions $(273.2 \mathrm{~K}, 101.33 \mathrm{kPa})$. The emission mass flow rates $(\mathrm{g} / \mathrm{s})$ were then calculated from the exhaust volume flow rate and emission concentrations, and were corrected for the background emission concentrations, temperature and humidity variations. Finally, distancebased emission factors $(\mathrm{g} / \mathrm{km})$ were calculated by integrating the instantaneous emission mass flow rates and vehicle speed. The fuel consumption rate $(\mathrm{L} / 100 \mathrm{~km})$ was calculated based on the principle of carbon mass balance.

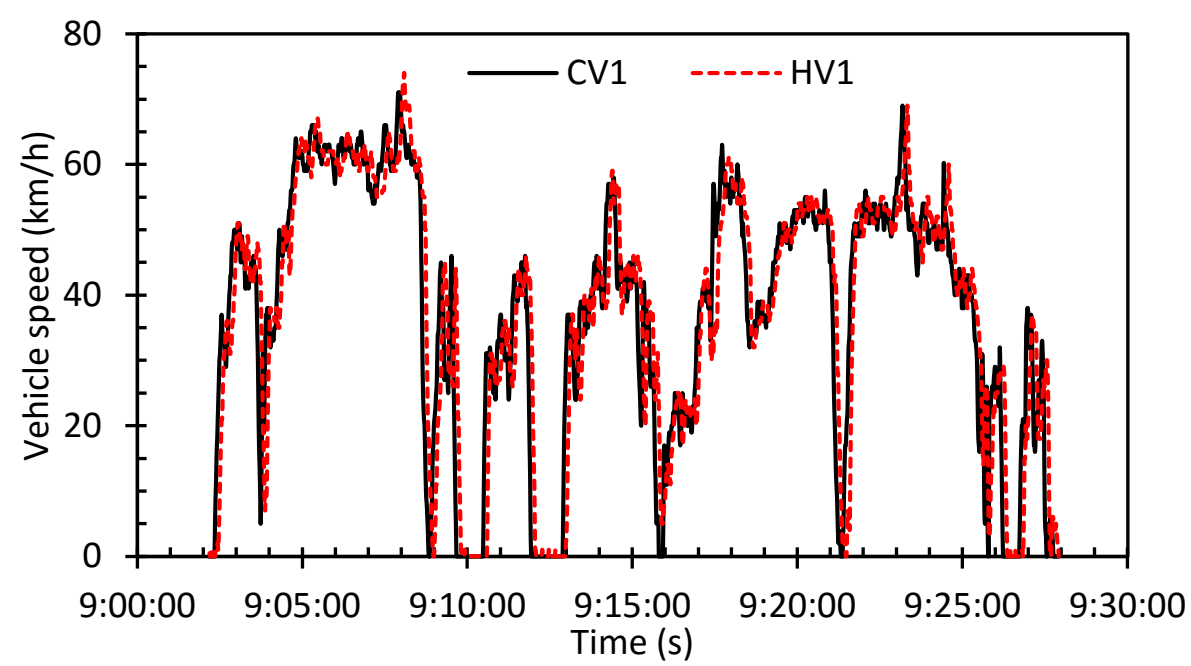

Fig. 3. Sample speed profiles of Lexus conventional (CV1) and hybrid (HV1) vehicles tested on the HK route on 17 July 2017.

Multivariate Analysis of Variance (MANOVA) was conducted to assess the statistical significance of the impact of the powertrain type, vehicle pair and test route (as independent variables) on fuel consumption and emissions (as dependent variables), using RStudio (Version 1.0.136). A Box-Cox transformation (Box and Cox, 1964) was employed to ensure that the dependent variables were normally distributed ( $P$-value range: $0.0826-0.280)$. The Box-Cox transformation is given by:

$$
y^{(\lambda)}=\left\{\begin{array}{cc}
\frac{y^{\lambda}-1}{\lambda}, & \text { if } \lambda \neq 0 \\
\log (y), & \text { if } \lambda=0
\end{array}\right.
$$

where $y$ is the original dependent variable, $\lambda$ is the transformation exponent and $y^{(\lambda)}$ is the transformed dependent variable. Maximum likelihood methods (Fox and Weisberg, 2011) were used to estimate $\lambda$. The manova function in $\mathrm{R}$ was used to test for the significance of the three factors on fuel consumption and emissions. The three-way interactions between powertrain type, vehicle pair and test route were considered. In addition to MANOVA analysis, a three-way Analysis of Variance (ANOVA) was conducted separately for each dependent variable. After ANOVA tests, Tukey HSD tests were performed to identify which pairwise comparisons were statistically significant (5\% alpha level). 


\section{Results and Discussion}

\subsection{Real-driving Fuel Consumption}

Fig. 4 compares the real-driving fuel consumption performance of the conventional and hybrid vehicles. The route-averaged fuel consumption rates were 9.83-12.64, 7.20-7.61, 14.35-19.34 and 8.35-10.58 L/100km for the Lexus conventional (CV1), Lexus hybrid (HV1), Alphard conventional (CV2) and Alphard hybrid (HV2) vehicles, respectively. Compared with the data published by the manufacturers (Table 1), the real-driving fuel consumption rates exceeded them by $30 \%-67 \%, 44 \%-52 \%, 35 \%-82 \%$ and $58 \%-100 \%$, respectively. In addition, all the four cars failed to meet the 2015 European average fuel economy target, which is $5.6 \mathrm{~L} / 100 \mathrm{~km}$ for petrol passenger car fleet (European Commission, 2018b). The $\mathrm{CO}_{2}$ emission profiles of conventional and hybrid cars (Fig. 5) showed the same tendencies as those observed in the fuel consumption rates, as the majority of fuel had been converted into $\mathrm{CO}_{2}$.

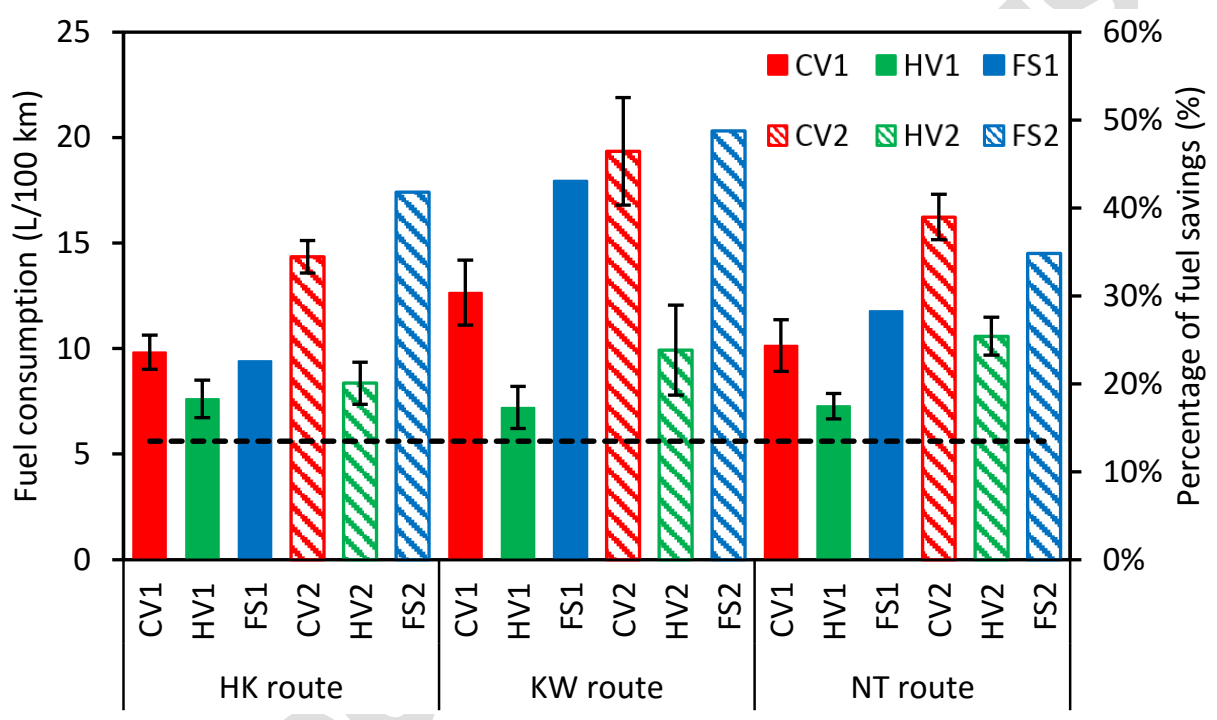

Fig. 4. Comparison of real-driving fuel consumption rates between conventional and hybrid vehicles, with standard deviations as error bars. The dashed line indicates the 2015 European average fuel economy target for petrol passenger car fleet. FS1 and FS2 represent the percentages of fuel savings of HV1 over CV1 and HV2 over CV2, respectively.

The significantly higher RDE fuel consumption and $\mathrm{CO}_{2}$ emissions than manufacturer values are expected and have been repeatedly reported in recent studies for different vehicle types. Rašić et al. (2017) investigated the RDE performance of a Euro 5 factory bi-fuel CNG/gasoline lightduty vehicle. The results showed that $\mathrm{CO}_{2}$ emissions exceeded the type-approval limits by $6 \%-35 \%$ with CNG and by 66\%-85\% with gasoline. Franco et al. (2016) reported that the on-road $\mathrm{CO}_{2}$ emissions of three diesel HEVs were higher than the certification values by $52 \%-178 \%$. PEMS measurements on 12 light-duty vehicles, including five Euro 3-5 gasoline vehicles, one Euro 4 gasoline HEV and six Euro 3-5 diesel vehicles, showed that on-road $\mathrm{CO}_{2}$ emissions were higher than the laboratory emission levels by $21 \pm 9 \%$ (Weiss et al., 2011). Duarte et al. (2016) found that the RDE fuel consumption was on average $23.9 \%$ and $16.3 \%$ higher than certification values of 
NEDC and WLTP Class 3 cycle respectively based on 16 Euro 5 light duty vehicles, including 11 conventional compression-ignition (CI) engines, two conventional spark-ignition (SI) engines and three hybrid SI engines. The discrepancy between laboratory and RDE results is likely caused by a number of factors, including certification margins, vehicle mass, aerodynamics, rolling resistance, ambient temperature, electric auxiliaries, road grade, air conditioning system and traffic conditions (Fontaras et al., 2017). However, a direct comparison on the RDE performance between hybrid and conventional vehicles could not be made because the vehicles used in above studies were in different models or classes and were tested under different conditions.

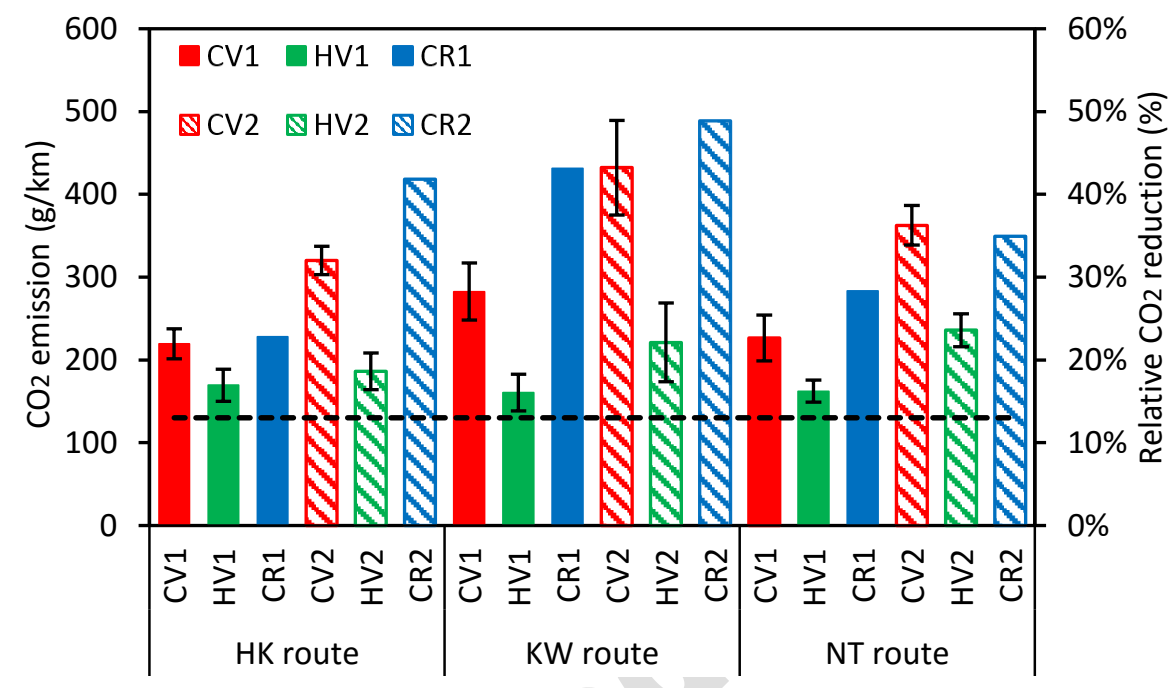

Fig. 5. Comparison of real-driving $\mathrm{CO}_{2}$ emissions between the conventional and hybrid vehicles, with standard deviations as error bars. The dashed line indicates the 2015 European average $\mathrm{CO}_{2}$ emission target for petrol passenger car fleet. CR1 and CR2 represent the percentages of $\mathrm{CO}_{2}$ reduction of HV1 over CV1 and HV2 over CV2, respectively.

In this study, each pair of conventional and hybrid vehicles were of the same model and were driven at the same time in a convoy mode, and thus eliminated the effects of vehicle configuration, driving behaviour, traffic conditions and ambient conditions on the performance comparison. As shown in Fig. 4, the two HEVs show clear advantages in fuel consumption over their ICE counterparts under real driving conditions, with fuel savings of 23\%-43\% for Lexus series and $35 \%-49 \%$ for Alphard series. The fuel savings are in the same ranges as those claimed by the manufacturers (34\% for Lexus and 50\% for Alphard, as shown in Table 1). This demonstrates that hybridisation could be a potential and effective technology to contribute to the $30 \%$ abatement task in road transport section of the Paris Agreement (European Commission, 2018a). The fuel savings of hybrid vehicles are mainly due to the advantages of the hybrid concept, which aims to minimise fuel consumption under low engine efficiency conditions (e.g. idling and stop-and-go traffic). Further break down of the fuel consumption performance under different road conditions (Fig. 6) shows that the fuel savings of hybrid cars are more obvious under urban conditions (42\% for HV1 and $44 \%$ for HV2) due to their ability to reduce engine operation time under low efficiency conditions. However, the fuel savings become much smaller under rural (18\% for HV1 and 22\% 
for HV2) and highway (5\% for HV1 and 19\% for HV2) conditions. This implies that HEVs are more effective for densely populated cities like Hong Kong with heavy traffic congestion problems and a high intensity of stop-start traffic.

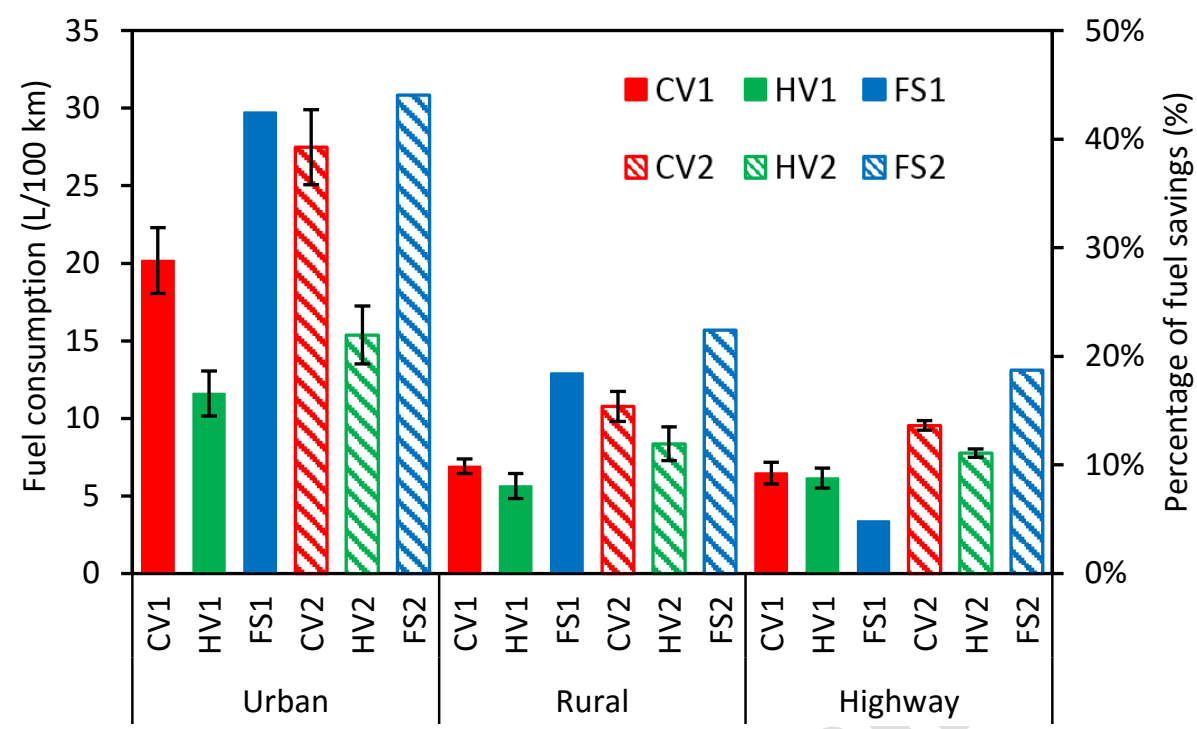

Fig. 6. Comparison of real-driving fuel consumption rates between conventional and hybrid vehicles under different driving conditions on the NT route, with standard deviations as error bars. FS1 and FS2 represent the percentages of fuel savings of HV1 over CV1 and HV2 over CV2, respectively.

\subsection{Real-driving Pollutant Emissions}

Fig. 7 compares the real driving emission performance of $\mathrm{CO}, \mathrm{HC}$ and $\mathrm{NO}$ between hybrid and conventional vehicles. As shown in Fig. 7, the three types of emissions were well below the Euro 5 emission limits for both hybrid and conventional vehicles on all the test routes, especially HC emissions. When comparing with conventional vehicles, only HV2 showed obvious reduction in NO emissions over CV2 (see Table 4 in section 3.3), while no reduction in HC emissions was observed for HV1 or HV2 (see Tables 4 and 5). Unexpectedly, both HV1 and HV2 showed consistently higher CO emissions than their ICE counterparts CV1 and CV2 (Fig. 7a) (see Tables 4 and 5), which may be caused by the following three reasons. Firstly, HEVs need to stop and restart the ICEs frequently to keep them working in the high efficiency region, especially under city driving conditions with stop-and-go traffic. Experimental results showed that although $10 \mathrm{~s}$ idling consumed more fuel than restarting, restarting produced much higher $\mathrm{CO}, \mathrm{HC}$ and NO emissions than a short idling did (e.g. 30 s) (Gaines et al., 2012). Secondly, engine stop-and-restart leads to larger variation in the exhaust gas temperature, and consequently larger temperature variations in the three-way catalyst (TWC) of hybrid cars. This would affect the conversion efficiency of the TWC. As shown in Fig. 8, the exhaust temperatures of both HEVs dropped more quickly than those of conventional vehicles during low speed and idling conditions. Thirdly, higher power may be required for the ICEs of HEVs because of the demand from both the wheels and batteries, which would produce higher CO emissions. 

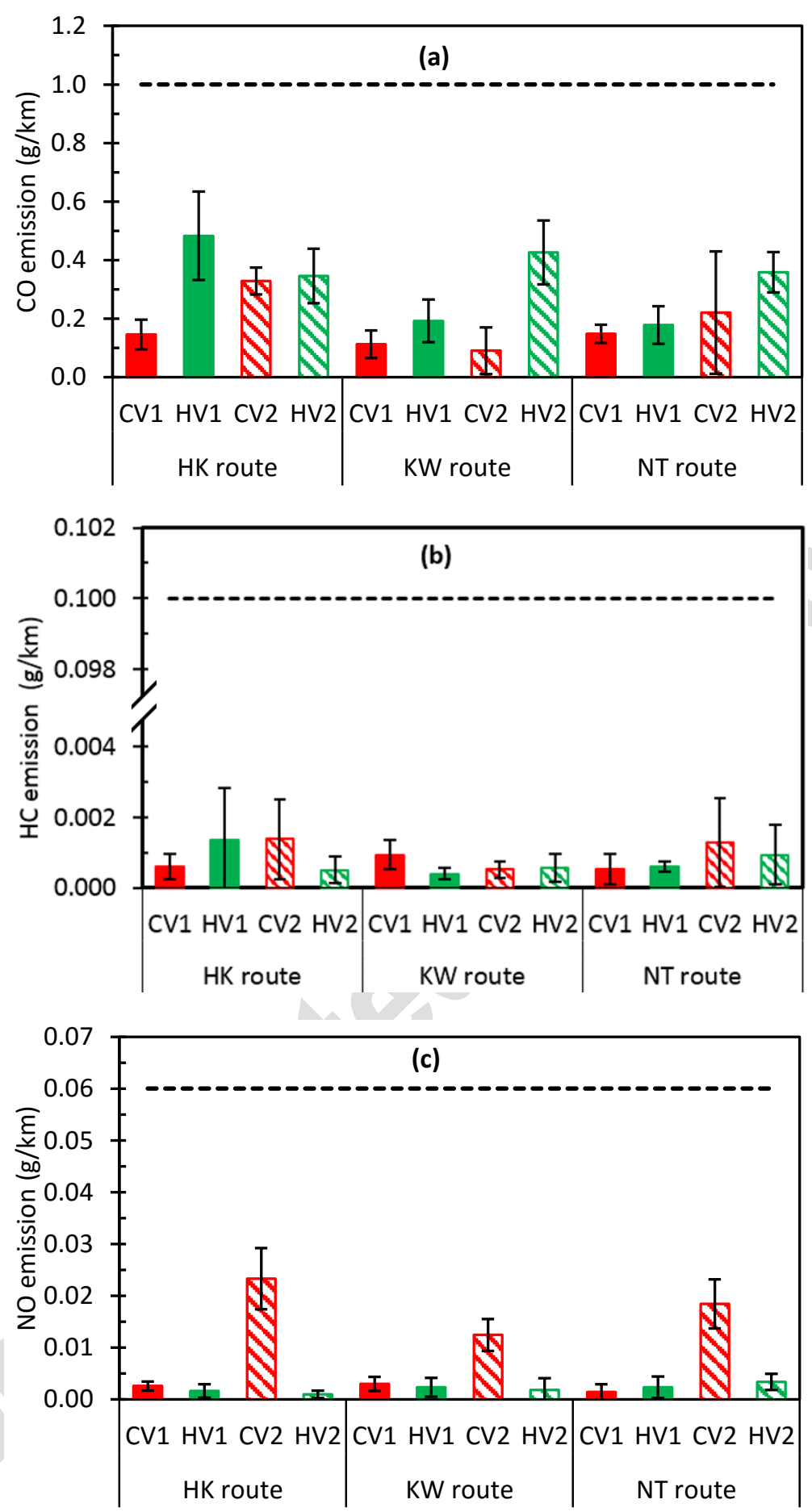

Fig. 7. Real-driving CO (a), HC (b) and NO (c) emissions of conventional and hybrid vehicles, with error bars indicating the standard deviations and dashed lines indicating the Euro 5 limits. 

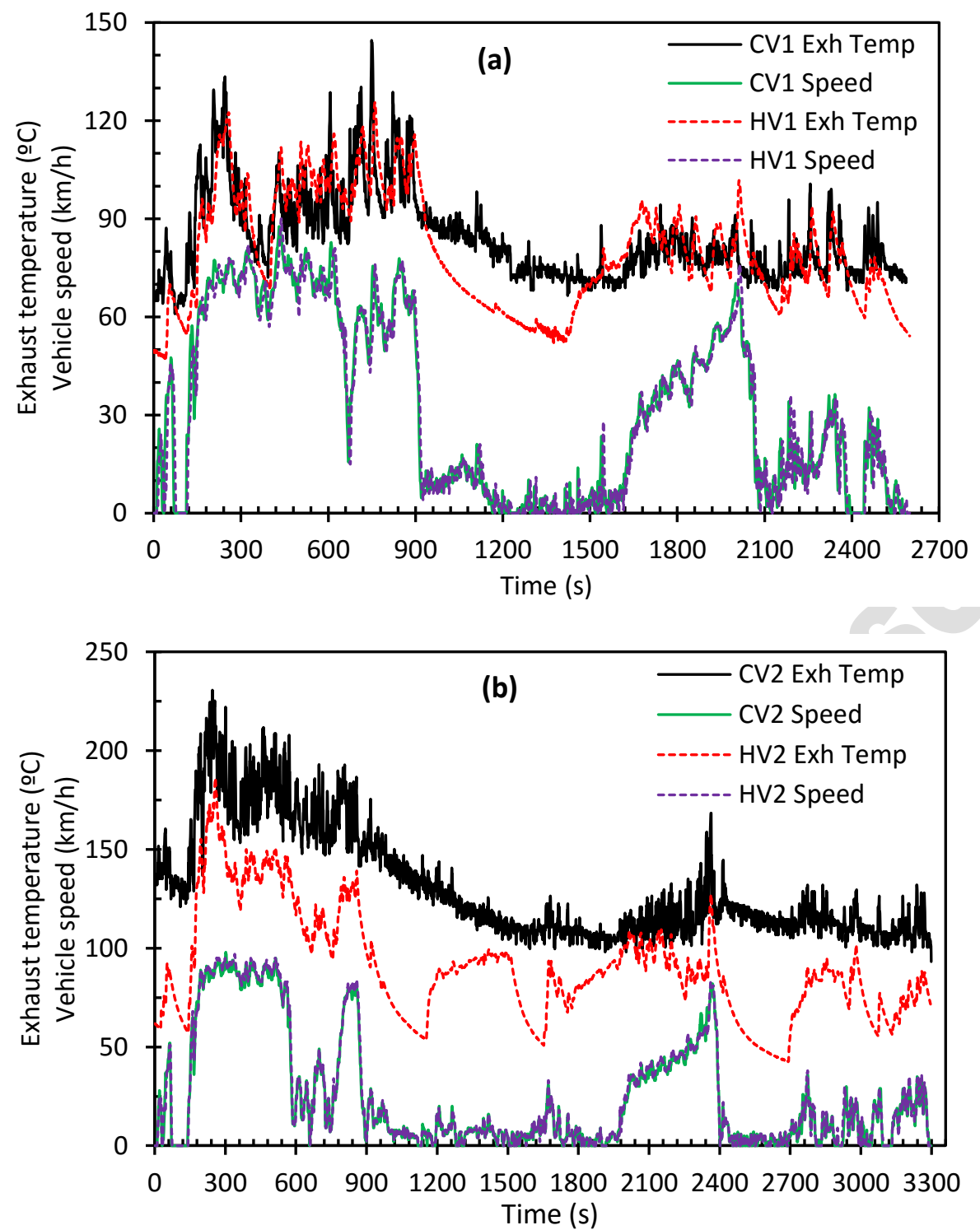

Fig. 8. Comparison of instantaneous exhaust gas temperatures and vehicle speeds between the hybrid and conventional vehicles of Lexus (a) and Alphard (b) series on the NT route.

\subsection{Uncertainties, Statistical Analysis and Implications}

A real world driving study will inevitably have many variations and uncertainties in the measurements. As each pair of vehicles were tested at the same time from Monday to Friday in a convoy mode using two sets of PEMSs, the effects of driving behaviour (speed, acceleration and braking), road conditions (road grade and traffic) and ambient environment (temperature, humidity and pressure) on the performance comparison between the conventional and hybrid vehicles were minimized. In addition, each pair of vehicles were of the same model so that the effects of vehicle configurations such as shape, weight and after-treatment system, would have insignificant influence on the performance comparison. The four vehicles were relatively new $(<$ two years old) and well maintained. The largest uncertainties in this study would come from the sensitivities of the emission analysers, which were two in-house PEMSs. All the four test vehicles were relatively clean and the exhaust emission concentrations were mostly very low. However, the PEMS 
resolutions were only $0.01 \%$ for $\mathrm{CO}$ and $1 \mathrm{ppm}$ for $\mathrm{HC}$ and NO. In addition to the convoy measurement approach described above, extra efforts were made to limit effects regarding measurement resolution by performing span checks for the two PEMSs before each test and repeating each test five times. Finally, our tests did not attempt to replicate the European RDE type approval process. This was because the RDE test boundaries were not applicable for Hong Kong driving conditions and needed to be adapted to local conditions accordingly. For example, the speed range of the standard RDE test is $0-160 \mathrm{~km} / \mathrm{h}$ (ICCT, 2017b) while the speed limits of most Hong Kong expressways are mostly 70,80 or $100 \mathrm{~km} / \mathrm{h}$ (one exception is the North Lantau Highway with the highest limit of $110 \mathrm{~km} / \mathrm{h}$ ). The three routes tested covered the typical urban, rural and highway driving conditions and represented three common daily trips in Hong Kong.

To examine the statistical significance of our results, MANOVA and ANOVA analysis was performed. Table 3 shows that a statistically significant three-way interaction $\left(P=2.13 \times 10^{-2}\right)$ exists between the three independent variables, i.e. powertrain, vehicle pair and test route. As a result, interpreting the statistical significance of the vehicle testing results relies on these three variables being considered simultaneously for reliable comparisons.

Table 3. MANOVA results on complete dataset.

\begin{tabular}{lcccccc}
\hline Source of variation & $\begin{array}{c}\text { Degrees of } \\
\text { freedom }\end{array}$ & $\begin{array}{c}\text { Pillai test } \\
\text { statistic }\end{array}$ & $\begin{array}{c}\text { Numerator } \\
\text { degrees of } \\
\text { freedom }\end{array}$ & $\begin{array}{c}\text { Denominator } \\
\text { degrees of } \\
\text { freedom }\end{array}$ & F & $P(>\mathrm{F})$ \\
\hline Powertrain & 1 & 0.892 & 5 & 44 & 72.6 & $<2.2 \times 10^{-16}$ \\
Vehicle pair & 1 & 0.774 & 5 & 44 & 30.1 & $3.64 \times 10^{-13}$ \\
Route & 2 & 0.646 & 10 & 90 & 4.30 & $6.61 \times 10^{-5}$ \\
Powertrain $\times$ vehicle pair & 1 & 0.786 & 5 & 44 & 32.4 & $1.08 \times 10^{-13}$ \\
Powertrain $\times$ Route & 2 & 0.541 & 10 & 90 & 3.33 & $1.01 \times 10^{-3}$ \\
Vehicle pair $\times$ Route & 2 & 0.322 & 10 & 90 & 1.73 & $8.63 \times 10^{-2}$ \\
$\begin{array}{l}\text { Powertrain } \times \text { Vehicle pair } \\
\times \text { Route }\end{array}$ & 2 & 0.400 & 10 & 90 & 2.25 & $2.13 \times 10^{-2}$ \\
Residuals & 48 & & & & & \\
\hline
\end{tabular}

Table 4 shows the three-factor ANOVA results for $\mathrm{HC}, \mathrm{CO}, \mathrm{NO}, \mathrm{CO}_{2}$ and fuel consumption. For HC emissions, a statistically significant three-way interaction exists $\left(P=2.66 \times 10^{-3}\right)$ between powertrain type, vehicle pair and test route. Despite this, none of the independent variables is significant when considered on their own. Hence, it can be concluded that $\mathrm{HC}$ emissions do not change with the powertrain, vehicle pair or test route selected. For CO emissions, a statistically significant three-way interaction exists $\left(P=2.60 \times 10^{-4}\right)$ between the three variables. A statistically significant two-way interaction exists $\left(P=8.38 \times 10^{-2}\right)$ between powertrain type and test route. Therefore $\mathrm{CO}$ emissions are impacted by all three independent variables. For example, when assessing the impact of powertrain on $\mathrm{CO}$ emissions, the vehicle pair and test route have to be taken into consideration too. For NO emissions, a statistically significant two-way interaction exists between powertrain type and vehicle pair $\left(P=2.27 \times 10^{-7}\right)$ and vehicle pair and test route $(2.8 \times$ $10^{-2}$ ). Hence, the effect of powertrain or test route depends on which vehicle pair is being 
considered. Finally, for fuel consumption, a statistically significant two-way interaction exists between all three pairs of independent variables i.e. powertrain type and vehicle pair $(P=4.27 \times$ $\left.10^{-2}\right)$, powertrain type and test route $\left(P=5.53 \times 10^{-3}\right)$ and vehicle pair and test route $(P=4.34 \times$ $\left.10^{-2}\right)$. Overall, all three independent variables should be considered when interpreting the fuel consumption results.

Table 4. $P(>F)$ values from three factor ANOVA analysis.

\begin{tabular}{lccccc}
\hline Source of variation & $\mathrm{HC}$ & $\mathrm{CO}$ & $\mathrm{NO}$ & $\mathrm{CO}_{2}$ & Fuel consumption \\
\hline Powertrain & 0.210 & $1.73 \times 10^{-7}$ & $1.62 \times 10^{-9}$ & $<2 \times 10^{-16}$ & $<2 \times 10^{-16}$ \\
Vehicle pair & 0.702 & $1.35 \times 10^{-2}$ & $8.79 \times 10^{-8}$ & $<2.26 \times 10^{-14}$ & $5.19 \times 10^{-15}$ \\
Route & 0.497 & $5.02 \times 10^{-4}$ & 0.970 & $2.43 \times 10^{-3}$ & $7.41 \times 10^{-4}$ \\
Powertrain $\times$ Vehicle pair & 0.112 & 0.394 & $2.27 \times 10^{-7}$ & 0.254 & $4.27 \times 10^{-2}$ \\
Powertrain $\times$ Route & 0.581 & $8.38 \times 10^{-2}$ & 0.109 & $1.28 \times 10^{-2}$ & $5.53 \times 10^{-3}$ \\
Vehicle pair $\times$ Route & 0.241 & 0.647 & $2.8 \times 10^{-2}$ & $5.27 \times 10^{-2}$ & $4.34 \times 10^{-2}$ \\
$\begin{array}{l}\text { Powertrain } \times \text { Vehicle pair } \\
\times \text { Route }\end{array}$ & $2.66 \times 10^{-3}$ & $2.60 \times 10^{-4}$ & 0.679 & 0.169 & 0.257 \\
\hline
\end{tabular}

Table 5 shows the multiple comparison test results. For HC, none of the pairwise comparison was statistically significant. Hence, neither powertrain, vehicle pair nor test route led to statistically significant changes in $\mathrm{HC}$ emissions. For $\mathrm{CO}$, there is evidence to suggest that $\mathrm{CO}$ emissions are higher with the hybrid powertrain $\left(P=6.21 \times 10^{-5}\right)$ specifically for the Toyota vehicles $(P=7.28$ $\left.\times 10^{-3}\right)$. For NO, emissions are higher for the Toyota vehicles $\left(P=1.68 \times 10^{-6}\right)$. Finally, for fuel consumption, all multiple comparisons are significant except for the difference in fuel consumption between the NT and HK route.

Table 5. $P(>|t|)$ values of multiple comparison tests.

\begin{tabular}{lccccc}
\hline Hypothesis tested & $\mathrm{HC}$ & $\mathrm{CO}$ & $\mathrm{NO}$ & $\mathrm{CO}_{2}$ & Fuel consumption \\
\hline Hybrid - Conventional & 0.18 & $6.21 \times 10^{-5}$ & 0.219 & $2.46 \times 10^{-4}$ & $5.22 \times 10^{-4}$ \\
Toyota - Lexus & $9.5 \times 10^{-2}$ & $7.28 \times 10^{-3}$ & $1.68 \times 10^{-6}$ & $2.62 \times 10^{-5}$ & $8.16 \times 10^{-6}$ \\
KW - HK & 0.508 & 0.740 & 0.984 & $7.71 \times 10^{-3}$ & $4.87 \times 10^{-3}$ \\
NT - HK & 0.851 & 0.995 & 0.304 & 0.934 & 0.926 \\
NT - KW & 0.231 & 0.684 & 0.229 & $1.96 \times 10^{-2}$ & $1.34 \times 10^{-2}$ \\
\hline
\end{tabular}

HEVs are regarded as an intermediate step in the move from ICEs to EVs, which have lower greenhouse and pollutant emissions than ICEs while avoiding the current bottlenecks of EVs (e.g. trade-offs between cost, energy density, weight and size of batteries, long recharging time and short driving range) (M. Sabri et al., 2016). HEVs and EVs have received significant government support to promote market penetration globally. Our results show that, although both hybrid and conventional vehicles exceed their respective laboratory fuel consumption and $\mathrm{CO}_{2}$ emission levels significantly, the relative advantages of hybrid vehicles over conventional vehicles in fuel savings 
(23-43\% for HV1 and 35-49\% HV2) are still in the same ranges as those of laboratory testing (34\% for HV1 and $50 \%$ for HV2). The advantages of hybrid vehicles are more obvious under urban driving conditions with low speeds and stop-and-go traffic. These results indicate that hybridisation is an effective technology to achieve the short-term target of greenhouse emission reduction under real driving conditions, e.g. 26\%-36\% in Hong Kong (Hong Kong SAR Government, 2018) and $30 \%$ in the EU (European Commission, 2018a) by 2030. Regarding pollutant emissions performance, however, this study challenges the widely accepted view that HEVs are cleaner than conventional ICE vehicles. Based on testing with statistical methods, our results showed that HEVs did not reduce $\mathrm{HC}$ emissions and only reduced NO emissions in a statistically significant manner for the second vehicle pair (i.e. HV2 vs CV2). The CO emissions of HEVs were higher than their conventional ICE counterparts in a statistically significant manner. This study implies that while HEVs are an important technology for achieving $\mathrm{CO}_{2}$ emission reduction targets, hybridisation may not bring the expected benefits to urban air quality. Future research is needed to develop cleaner ICEs and for HEVs to ensure better energy management systems and performance of aftertreatment systems. The state of charge (SOC) of the battery is a key parameter of the battery management systems, which largely determines the engine operation conditions of an HEV and consequently the fuel consumption and emissions performance (Hu et al., 2012; M. Sabri et al., 2016). Measuring the SOC data of HEVs (e.g. using a Toyota Scan Tool) can help better determine the engine operation conditions and thus further explore the underlying reasons of higher $\mathrm{CO}$ emissions from HEVs.

\section{Conclusions}

This study aimed to investigate the real-driving fuel consumption and pollutant emissions performance of HEVs against their conventional ICE counterparts. Two pairs of hybrid and conventional vehicles of the same model were recruited for RDE tests, which had the same vehicle configurations and thus enabled a fair performance comparison. Moreover, each pair of vehicles were tested on the same route simultaneously in a novel convoy mode using two PEMSs, which eliminated the effect of a number of uncontrollable real-driving conditions on the performance comparison. The major results of this study are:

1) Although real-driving fuel consumption rates for both hybrid and conventional vehicles were 44\%-100\% and 30\%-82\% higher than their laboratory results respectively, HEVs saved $23 \%$ $49 \%$ fuel than their conventional ICE counterparts. The relative advantages of HEVs over conventional ICE vehicles in fuel savings were in the same range as that reported in laboratory testing. The advantages of HEVs were more obvious under urban driving conditions with low speeds and stop-and-go traffic.

2) Pollutant emissions of all the test vehicles were lower than their regulation limits. However, HEVs showed no reduction in $\mathrm{HC}$ emissions and consistently higher $\mathrm{CO}$ emissions compared to the conventional ICE vehicles. This was caused by the frequent stops and restarts of the HEV engines, as well as the lowered exhaust gas temperature and reduced effectiveness of the oxidation catalyst. 
3) The results of this study show that while achieving the $\mathrm{CO}_{2}$ reduction target, hybridisation of the vehicle powertrain may not bring the expected benefits to urban air quality.

\section{Acknowledgements}

We acknowledge the support provided by the Inchcape Hong Kong Ltd.

\section{References}

G.E.P. Box, D.R. Cox, 1964. An Analysis of Transformations. J. Royal Stat. Soc. Series B 26, 211 252.

B. Degraeuwe, M. Weiss, 2017. Does the New European Driving Cycle (NEDC) really fail to capture the NOX emissions of diesel cars in Europe? Environ. Pollut. 222, 234-241.

G.O. Duarte, G.A. Gonçalves, T.L. Farias, 2016. Analysis of fuel consumption and pollutant emissions of regulated and alternative driving cycles based on real-world measurements. Transp. Res. Part D 44, 43-54.

T. Durbin, K. Johnson, J.W. Miller, et al., 2018. Editorial. Sci. Total Environ. 642, 1439-1440.

European Commission, 2017. EU action to curb air pollution by cars: Questions and Answers (MEMO/17/2821). European Commission - Fact Sheet.

European Commission, 2018a. Proposal for post-2020 CO2 targets for cars and vans. https://ec.europa.eu/clima/policies/transport/vehicles/proposal_en <accessed 05.12.2018>.

European Commission, 2018b. Reducing CO2 emissions from passenger cars. https://ec.europa.eu/clima/policies/transport/vehicles/cars_en <accessed 05.12.2018>.

G. Fontaras, N.-G. Zacharof, B. Ciuffo, 2017. Fuel consumption and CO2 emissions from passenger cars in Europe - Laboratory versus real-world emissions. Prog. Energy Combust. Sci. 60, 97-131.

J. Fox, S. Weisberg, 2011. An R companion to applied regression. Thousand Oaks, SAGE Publications.

V. Franco, T. Zacharopoulou, J. Hammer, et al., 2016. Evaluation of Exhaust Emissions from Three Diesel-Hybrid Cars and Simulation of After-Treatment Systems for Ultralow Real-World NOx Emissions. Environ. Sci. Technol. 50, 13151-13159.

M. Fu, Y. Ge, X. Wang, et al., 2013. NOx emissions from Euro IV busses with SCR systems associated with urban, suburban and freeway driving patterns. Sci. Total Environ. 452-453, 222-226.

L. Gaines, E. Rask, G. Keller, 2012. Which Is Greener: Idle, or Stop and Restart? Argonne National Laboratory, 1-2.

K.S. Gallagher, E. Muehlegger, 2011. Giving green to get green? Incentives and consumer adoption of hybrid vehicle technology. J. Environ. Econ. Manag. 61, 1-15.

J. Gallus, U. Kirchner, R. Vogt, et al., 2016. On-road particle number measurements using a portable emission measurement system (PEMS). Atmos. Environ. 124, 37-45.

H. Hao, X. Ou, J. Du, et al., 2014. China's electric vehicle subsidy scheme: Rationale and impacts. Energy Policy 73, 722-732.

H. He, J. Fan, Y. Li, et al., 2017. When to switch to a hybrid electric vehicle: A replacement optimisation decision. J. Clean. Prod. 148, 295-303. 
Hong Kong SAR Government, 2018. Climate Change. https://www.gov.hk/en/residents/environment/global/climate.htm <accessed 05.12.2018>.

X. Hu, S. Li, H. Peng, et al., 2012. Robustness analysis of State-of-Charge estimation methods for two types of Li-ion batteries. J. Power Sources 217, 209-219.

Y. Huang, G. Hong, R. Huang, 2015. Investigation to charge cooling effect and combustion characteristics of ethanol direct injection in a gasoline port injection engine. Appl. Energy $160,244-254$.

Y. Huang, E.C.Y. Ng, J.L. Zhou, et al., 2018a. Eco-driving technology for sustainable road transport: A review. Renew. Sustain. Energy Rev. 93, 596-609.

Y. Huang, B. Organ, J.L. Zhou, et al., 2018b. Emission measurement of diesel vehicles in Hong Kong through on-road remote sensing: Performance review and identification of highemitters. Environ. Pollut. 237, 133-142.

Y. Huang, B. Organ, J.L. Zhou, et al., 2018c. Remote sensing of on-road vehicle emissions: Mechanism, applications and a case study from Hong Kong. Atmos. Environ. 182, 58-74.

ICCT, 2017a. China's Stage 6 Emission Standard for New Light-Duty Vehicles (Final Rule). Policy Update, 1-13.

ICCT, 2017b. Real-Driving Emissions Test Procedure for Exhaust Gas Pollutant Emissions of Cars and Light Commercial Vehicles in Europe. Policy Update, 1-10.

IEA, 2017. World energy balances: Overview. International Energy Agency.

J. Khan, M. Ketzel, K. Kakosimos, et al., 2018. Road traffic air and noise pollution exposure assessment - A review of tools and techniques. Sci. Total Environ. 634, 661-676.

M. Kousoulidou, G. Fontaras, L. Ntziachristos, et al., 2013. Use of portable emissions measurement system (PEMS) for the development and validation of passenger car emission factors. Atmos. Environ. 64, 329-338.

S. Kwon, Y. Park, J. Park, et al., 2017. Characteristics of on-road NOx emissions from Euro 6 light-duty diesel vehicles using a portable emissions measurement system. Sci. Total Environ. 576, 70-77.

Lexus, 2018. Specificiations of Lexus NX300h and NX200t. http://www.lexus.com.hk/nx/300h/doc/final_Lexus_NX_AW_Aug14.pdf <accessed 05.12.2018>.

T. Liu, X. Hu, S.E. Li, et al., 2017. Reinforcement Learning Optimized Look-Ahead Energy Management of a Parallel Hybrid Electric Vehicle. IEEE ASME Trans. Mechatron. 22, 14971507.

W. Liu, 2013. Introduction to Hybrid Vehicle System Modeling and Control, First ed. Wiley.

M.F. M. Sabri, K.A. Danapalasingam, M.F. Rahmat, 2016. A review on hybrid electric vehicles architecture and energy management strategies. Renew. Sustain. Energy Rev. 53, 1433-1442.

C.M. Martinez, X. Hu, D. Cao, et al., 2017. Energy Management in Plug-in Hybrid Electric Vehicles: Recent Progress and a Connected Vehicles Perspective. IEEE Trans. Veh. Technol. $66,4534-4549$.

P. Mendoza-Villafuerte, R. Suarez-Bertoa, B. Giechaskiel, et al., 2017. NOx, NH3, N2O and PN real driving emissions from a Euro VI heavy-duty vehicle. Impact of regulatory on-road test conditions on emissions. Sci. Total Environ. 609, 546-555.

P. Mock, 2017. 2020-2030 CO2 standards for new cars and light-commercial vehicles in the European Union. The International Council on Clean Transportation. 
R. O'Driscoll, H.M. ApSimon, T. Oxley, et al., 2016. A Portable Emissions Measurement System (PEMS) study of NOx and primary NO2 emissions from Euro 6 diesel passenger cars and comparison with COPERT emission factors. Atmos. Environ. 145, 81-91.

R. O'Driscoll, M.E.J. Stettler, N. Molden, et al., 2018. Real world CO2 and NOx emissions from 149 Euro 5 and 6 diesel, gasoline and hybrid passenger cars. Sci. Total Environ. 621, 282290.

D. Rašić, S. Rodman Oprešnik, T. Seljak, et al., 2017. RDE-based assessment of a factory bi-fuel CNG/gasoline light-duty vehicle. Atmos. Environ. 167, 523-541.

A. Rezaei, J.B. Burl, A. Solouk, et al., 2017. Catch energy saving opportunity (CESO), an instantaneous optimal energy management strategy for series hybrid electric vehicles. Appl. Energy 208, 655-665.

C. Sun, F. Sun, H. He, 2017. Investigating adaptive-ECMS with velocity forecast ability for hybrid electric vehicles. Appl. Energy 185, 1644-1653.

UNECE, 2015. Regulation No 83 of the Economic Commission for Europe of the United Nations (UNECE) - Uniform provisions concerning the approval of vehicles with regard to the emission of pollutants according to engine fuel requirements [2015/1038]. Official Journal of the European Union 172, 1-249.

T. Wang, D.C. Quiros, A. Thiruvengadam, et al., 2017. Total Particle Number Emissions from Modern Diesel, Natural Gas, and Hybrid Heavy-Duty Vehicles During On-Road Operation. Environ. Sci. Technol. 51, 6990-6998.

M. Weiss, P. Bonnel, R. Hummel, et al., 2011. On-Road Emissions of Light-Duty Vehicles in Europe. Environ. Sci. Technol. 45, 8575-8581.

WHO, 2018. Ambient air pollution - a major threat to health and climate. http://www.who.int/airpollution/ambient/en/ <accessed 05.12.2018>.

S. Zahedi, J.M. Batista-Foguet, L. van Wunnik, 2019. Exploring the public's willingness to reduce air pollution and greenhouse gas emissions from private road transport in Catalonia. Sci. Total Environ. 646, 850-861.

X. Zheng, Y. Wu, S. Zhang, et al., 2016. Joint measurements of black carbon and particle mass for heavy-duty diesel vehicles using a portable emission measurement system. Atmos. Environ. $141,435-442$. 